\title{
The distinctly Canadian origins of cyclopropane
}

\author{
Kim E. Turner, BScPhm, MSc, MD, FRCPC
}

Received: 10 May 2018/Accepted: 10 May 2018/Published online: 31 May 2018

(C) Canadian Anesthesiologists' Society 2018

There was a worldwide quest during the early part of the 20th century to discover an anesthetic agent that could augment or replace the commonly used agents of the time namely ether, choloroform, and nitrous oxide. Among those pursuing this line of research was Dr. Velyien E. Henderson, Professor of Pharmacology at the University of Toronto, working with Dr. W. Easson Brown, an assistant in the University's Department of Pharmacology, who was an anesthesiologist at the Toronto General Hospital.

Their initial experimentation with propylene had shown promise when the gas was freshly prepared. After storage under pressure in steel tanks, however, its administration induced nausea and cardiac irregularities. Dr. George H. Lucas, a new chemist working with Dr. Henderson, wondered if the toxic contaminant might be cyclopropane, formed when propylene is prepared. Indeed, his analysis of the stored propylene revealed that its isomer, cyclopropane, was also present in the stored tank. In 1928, Dr. Lucas subsequently isolated and purified a sample of cyclopropane, believing it to be a toxic compound. ${ }^{1}$ To his great surprise, when the cyclopropane was tested on two kittens in a bell jar, "the animals went to sleep quietly ... and recovered rapidly". ${ }^{2}$ After further study, Dr. Brown administered cyclopropane to Dr. Henderson, the first human to receive cyclopropane. Several demonstrations of cyclopropane's use on other members of the laboratory staff (including Dr. Lucas) soon followed. ${ }^{2}$ The Toronto group went on to further

\section{K. E. Turner, BScPhm, MSc, MD, FRCPC ( $\square)$}

Department of Anesthesiology \& Perioperative Medicine and Public Health Sciences, Medical Lead Health Quality Programs, Queen's University, Kingston, ON, Canada

e-mail: Kim.Turner@kingstonhsc.ca

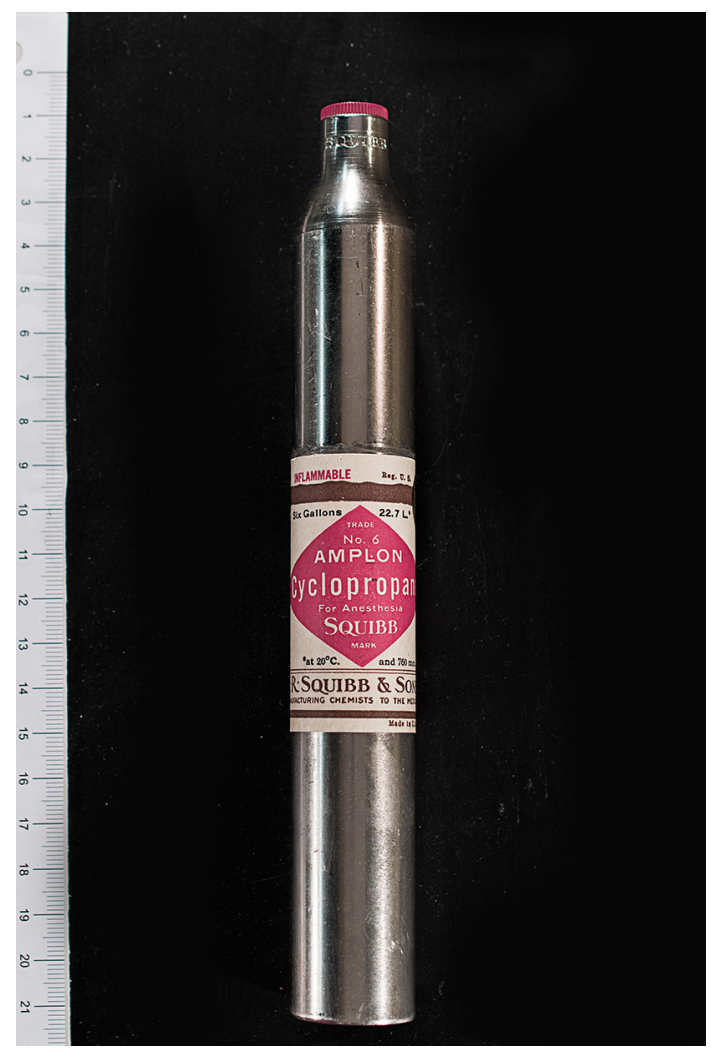

Figure "No. 6 Amplon" cylinder (the tradename assigned by the manufacturer E.R. Squibb and Sons) was designed to yield 6 gallons $(22.7 \mathrm{~L})$ of cyclopropane administered at a concentration of $12-35 \%$. In a series of 350 cases reported in 1934, Dr. Griffith estimated that he used an average of 1.79 gallons per case at a cost of 50 cents per gallon that, although costly at the time, was considerably less expensive than when the gas was first produced at $\$ 2.00$ per gallon. ${ }^{6}$ (Image courtesy of the RBC Art and Heritage Centre of McGill University Health Centre) 
characterize cyclopropane's pharmacology and physical properties, including its explosive nature in air or oxygen when at anesthetic concentrations. While studying the latter property, Dr Lucas recorded in his laboratory book after intentionally exploding a $100-\mathrm{mL}$ gas pipette with a $16 \%$ cyclopropane mixture in oxygen - that it "Blew all to hell". ${ }^{2}$

Unfortunately, a series of highly publicized deaths ${ }^{3}$ attributed to the administration of anesthesia prevented further clinical experimentation with cyclopropane in Toronto, despite a public demonstration in which Sir Frederick Banting was anesthetized. ${ }^{1,2}$ Fortunately, Dr. Ralph Waters at the University of Wisconsin, via correspondence with Dr. Henderson, was able to continue these investigations which led to the eventual clinical introduction of cyclopropane in $1934 .^{3}$

Shortly after gaining experience with the new agent, Dr. Harold Griffith, expressed the opinion that, "My conception of anaesthesia with the older gases is that we administer the gas, plus enough oxygen to keep the patient alive and in good condition. With cyclopropane, on the other hand, we administer oxygen with just enough of the anaesthetic gas to keep the patient asleep". ${ }^{4}$
Cyclopropane, a Canadian discovery, remained one of the mainstays of anesthesia practice until being replaced by halothane in 1956, the long-awaited first inhaled agent to reduce the risk of anesthetic-related fire and explosion.

Conflicts of interest None declared.

Editorial responsibility This submission was handled by Dr. Hilary P. Grocott, Editor-in-Chief, Canadian Journal of Anesthesia.

\section{References}

1. Lucas GH. The discovery and pharmacology of cyclopropane. Can Anaesth Soc J 1960; 7: 237-56.

2. Lucas GH. The discovery of cyclopropane. Anesth Analg 1961; 40: 15-27.

3. Turner KE. Cyclopropane: a varsity gift to mankind. In: Byrick RJ (Ed.). A Commemorative History of the Department of Anaesthesia, University of Toronto. Department of Anaesthesia, University of Toronto; 2004: 71-87.

4. Griffith HR. Cyclopropane anaesthesia: a clinical record of 350 administrations. Can Med Assoc J 1934; 31: 157-60. 